\title{
Generation of Oxygen, Carbon and Metallic Ion Beams by a Compact Microwave Source*
}

S. R. Walther, K. N. Leung, K. W. Ehlers, and W. B. Kunkel

\author{
Lawrence Berkeley Laboratory \\ University of California \\ Berke 7ey, CA 94720 \\ U. S. A.
}

LBL -21917

July 1986

DE87 000045

\section{DISCLAIMER}

\begin{abstract}
This report was prepared as an account of work sponsored by an agency of the United States Government. Neither the United States Government nor any agency thereof, nor any of their empłoyes, makes any warranty, express or imptied, or assumes any lezal liability or responsitility for the accuracy, compteteness, or usefulness of any information, apparatus, product, or process discloced, or represents that its use would not infringe privately owned rithts. Reference herein to any specific commercial product, process, or service by trade name, trademark, manufacturer, or otberwise does not necessarily constitute or imply its endorsement, rocommendation, or favoring by the United States Government or any asency thereof. The views and opinioas of authors expreased berein do not necessarily state or reflect thone of the United States Government or any agency thereof.
\end{abstract}

\section{\#This work is supported by the Air Force office of Scientific Research and the U.S. DOE under Contract NO. DE-ACO3-76SF00098.}


Generation of Oxygen, Carbon and Metallic Ion Beams by a Compact Microwave Source*

S. R. Walther, K. N. Leung, K. W. Ehlers, and W. B. Kunkel

$$
\begin{gathered}
\text { Lawrence Berkeley Laboratory } \\
\text { Uriversity of California } \\
\text { Berkeley. CA } 94720 \\
\text { U. S. A. }
\end{gathered}
$$

\section{Abstract}

A small microwave ton source fabricated from a quartz tube and unclosed externally by a cavity has been operated with different geometries and for various gases in a $\mathrm{Cw}$ mode. This source has been used to generate oxygen fon beans with energy as low as $5.5 \mathrm{eV}$. Bean energy spread has been measu-ed to be less than $r e v$. By installing different metal plates on the front extraction electrode, metallic ion beams such as (Be, CU, Al, etc.) can be produced. It has also been demonstrated that the source can be used to form steady state beans of volume-produced negative fons such as $\mathrm{H}^{-}, \mathrm{Li}^{-}$and $\mathrm{C}^{-}$.

*This work is supported by the Air Force office of Scientific Research and the U.S. DOE under Contract NO. DE-ACO3-76SF00098. 


\section{Introduction}

In recent years, there has been extensive research and development of fon sources for ion implantation and ion beam etching in the semi-conductor industry. The compact microwave ion source ${ }^{7}$ newly developed at Lawrence Berkeley Laboratory is well suited to these applications. This source can be made quite small, and requires only one power supply for the whole source operation. There are no lifetime-iimited components such as filaments or cathodes, so stable $\mathrm{cw}$ operation is possible for long periods of time even for reactive gases. Since there is no magnetic field in the extraction region, the bean optics for this source should be better than most ECR sources. This microwave source has been operated successfully to generate positive ion beams of gases such as $\mathrm{H}_{2}$, hie, Me, Ar, and $X_{e}$. Experinents conducted at the

Los Alamos Mational Laboratory denonstrated that the fon energy spread for the source is extremely smali $(<1 \mathrm{eV}) .^{2}$ In this paper, details of the arrangement for the production of low energy oxygen ion beans, positive and negative carbon ion beans, and metallic ion beans is presented.

\section{Experimental apparatus:}

The microwave ion source, as show in Fig. 1, is fabricated from a quartz tube with one end enclosed by a piasma electrode and a gas inlet at the other end. This tube is formed by joining a section of quartz tube with a $10 \mathrm{~mm}$ outside diameter to a section of a larger tube with a $27 \mathrm{~mm}$ outside dianeter. The smaller tube is enclosed by a microwave cavity operating at a frequency of $2.45 \mathrm{GHz}$. Microwave power as high as $500 \mathrm{~W}$ can be coupled to the cavity via a coaxial cable. Cooling air is directed at the discharge tube through an opening in the body of the cavity. Additional cooling of the source is 
provided by an air blower. Ionization of the gas in the tube is initiated by a hand-held Tesla coil. A tuning stub and coupling slider are provided in the cavity to properly match the impedance of the discharge to that of the generator. Forward and reflected microwave power are measured using a bi-directional power meter. Ion beam energy and species composition are both determined with the help of a compact magnetic-deflection spectrometer. 3

\section{Experimental Results}

(a) Low energy oxygen ion beams

In order to generate low energy positive oxygen ion beams, the source is operated without any externally applied extraction voltage. The positive ions (and some electrons) are self-extracted from the source due to the positive plasma potential. The energy of the bean ions striking a target surface is equal to the difference between the plasma potential and the target potential: If the target is an insulator, then it can be charged to a positive potential and the resultant ion impact energy is reduced. For a conducting target, however, it can be at ground or zero potential and the ton impact energy is equal to the plasma potential.

Initial measurements showed that the oxygen tons were escaping from the source with energies between 15 and $20 \mathrm{eV}$. In order to obtain a lower ion energy, the source plasma potential was reduced by instaling a magnetic filter in front of the plasma electrode. With this filter arrangenent, an ion beam energy as low as 5 ev was achieved. 4

A single $0.8 \mathrm{~mm}$ dianeter nole was initially employed to extract a positive Ion bean from the microwave source. In order to increase the fon flux, a new extractor with $250.8 \mathrm{~m}$-dian holes was fabricated. The resulting beam 
current was $\sim 18$ times larger than that of the single aperture and it could be used to irradiate large target areas. To further improve the selfextracted bean current, a $70 \%$ transparent tungsten screen of $1 \mathrm{~cm}-\mathrm{d}$ iam was used in place of the 25 small noles. The combination of a magnetic filter and the tungsten screen extraction system produced a nearly gaussian beam profile as shown in Fig. 2 with flux rate $>1 \times 10^{14} \mathrm{~cm}^{-2} \mathrm{~s}^{-1}$ at the lowest beam energy. The distribution of $\mathrm{O}^{+}$and $\mathrm{O}_{2}^{+}$ions is about equal.

(b) Production of positive and negative carbon ion beans

$\mathrm{C}^{+}$ion beams can be easily generated by this microwave source by using gases such as $\mathrm{CO}, \mathrm{CO}_{2}$, or $\mathrm{CH}_{4}$. In addition to $\mathrm{C}^{+}$ions, the spectrometer output signal shows that positive ions of other radicals such as $\mathrm{CO}_{2} \mathrm{CO}_{2}, 0$, $\mathrm{O}_{2}$ etc are present. A pure $\mathrm{C}^{+}$bean can only be obtained after the extracted beam is mass analyzed. Attempts have been made to produce $C^{-}$ions by using these gases. However, no $\mathrm{C}^{-}$ion signal can be detected for different source operating conditions. By replacing the first or plasma electrode of the extractor with a graphite disc together with a negative bias, a large $\mathrm{C}^{-}$ion signal is observed (Fig. 3 ). In this arrangenent, some carbon atoms are sputtered from the graphite electrode by the background $\mathrm{Ar}^{+}$ ions. They then react with the plasma electrons to form $\mathrm{c}^{-}$ions.

\section{(c) Production of metalitic ion beans}

Different positive metallic ion beams (such as $\mathrm{Be}, \mathrm{Al}$ or $\mathrm{CU}$ ) have been produced in a source arrangement similar to that used for generating $\mathrm{c}^{-}$ beams. In this case, oniy a portion of the plasma electrode around the extraction aperture is replaced by the target metal which now forms the second 
electrode of the extraction system. The metal is biased several hundred volts negative with respect to the plasma electrode to allow ion sputtering. The metal atoms removed by sputtering can be ionized by the energetic electrons, and the positive ions formed will fall back into the sheath and are then avaliable for extraction. Production of different metallic ions by this source geometry is in progress. Results of these study will be reported in the near future.

\section{Acknowledgment}

We would like to thank D. Moussa, D. Kippenhan and M. D. Williams for technical assistance. This work is supported by the Air Force office of Scientific Research and the U.S. DOE under Contract NO. DE-AC03-76SF00098.

\section{References}

1. S. R. Walther, K. M. Leung, and W. B. Kunkel, Rev. Sci. Instrun. 57, Aug. (1986).

2. E. Chamberlin, Los Alamos Mational Laboratory (Private communication).

3. K. W. Ehlers, K. W. Leung, and M. D. Wtllitans, Rev. Sct. Instrum. 50, 1031 (1979).

4. S. R. Walther, K. N. Leung, and W. B. Kunke1, Lawrence Berkeley Lab. Report LBL-21376, May (1986). 


\section{Figure Captions}

1. Schematic diagram of the microwave ion source.

2. Low energy oxygen ion beam profile of the source using a tungsten screen plasma electrode and filter magnets.

3. Spectrometer output signal showing the presence of $\mathrm{C}^{-}$tons in the beam. 


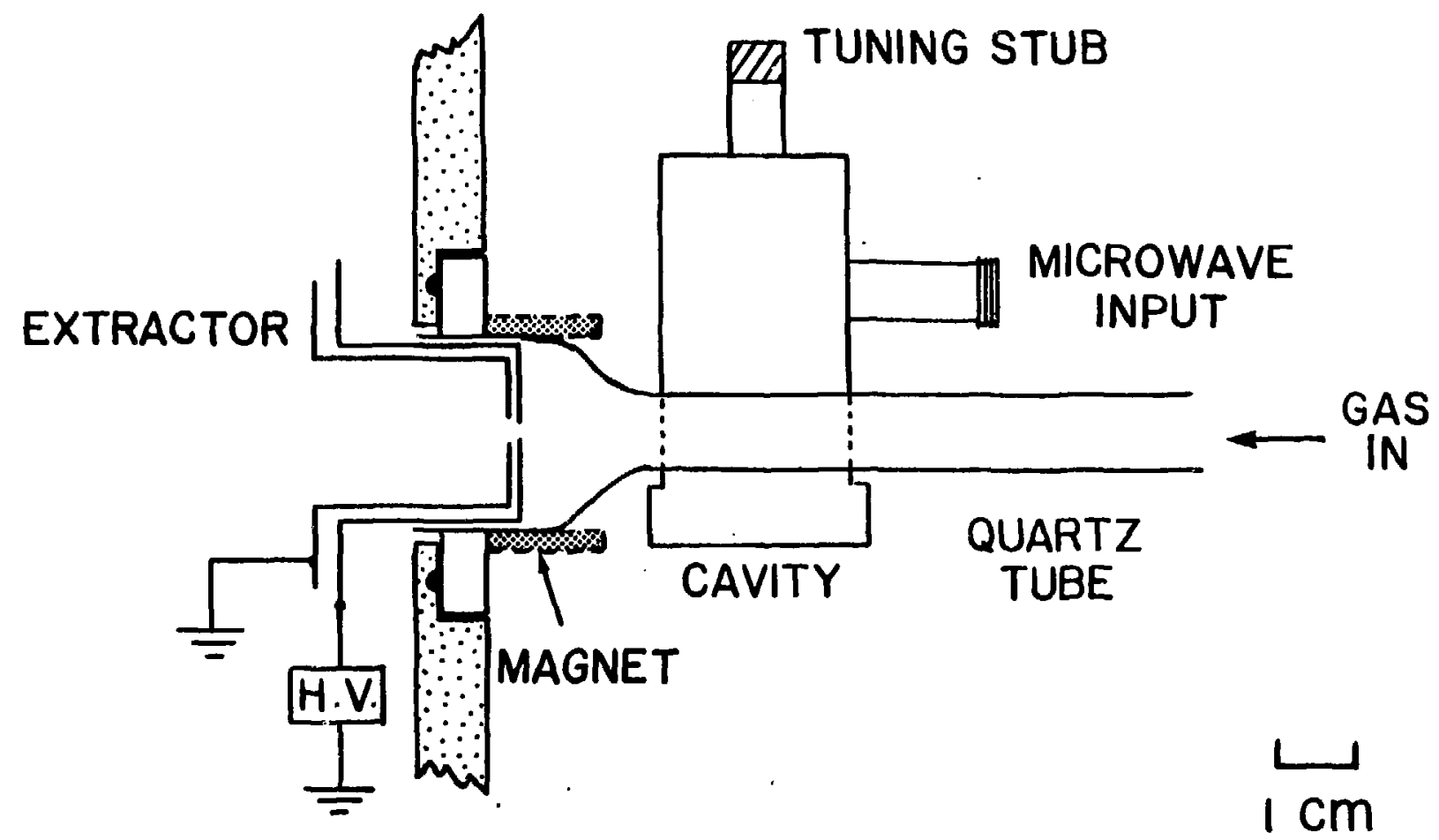

XBL 8512-5133

Fig. 1 


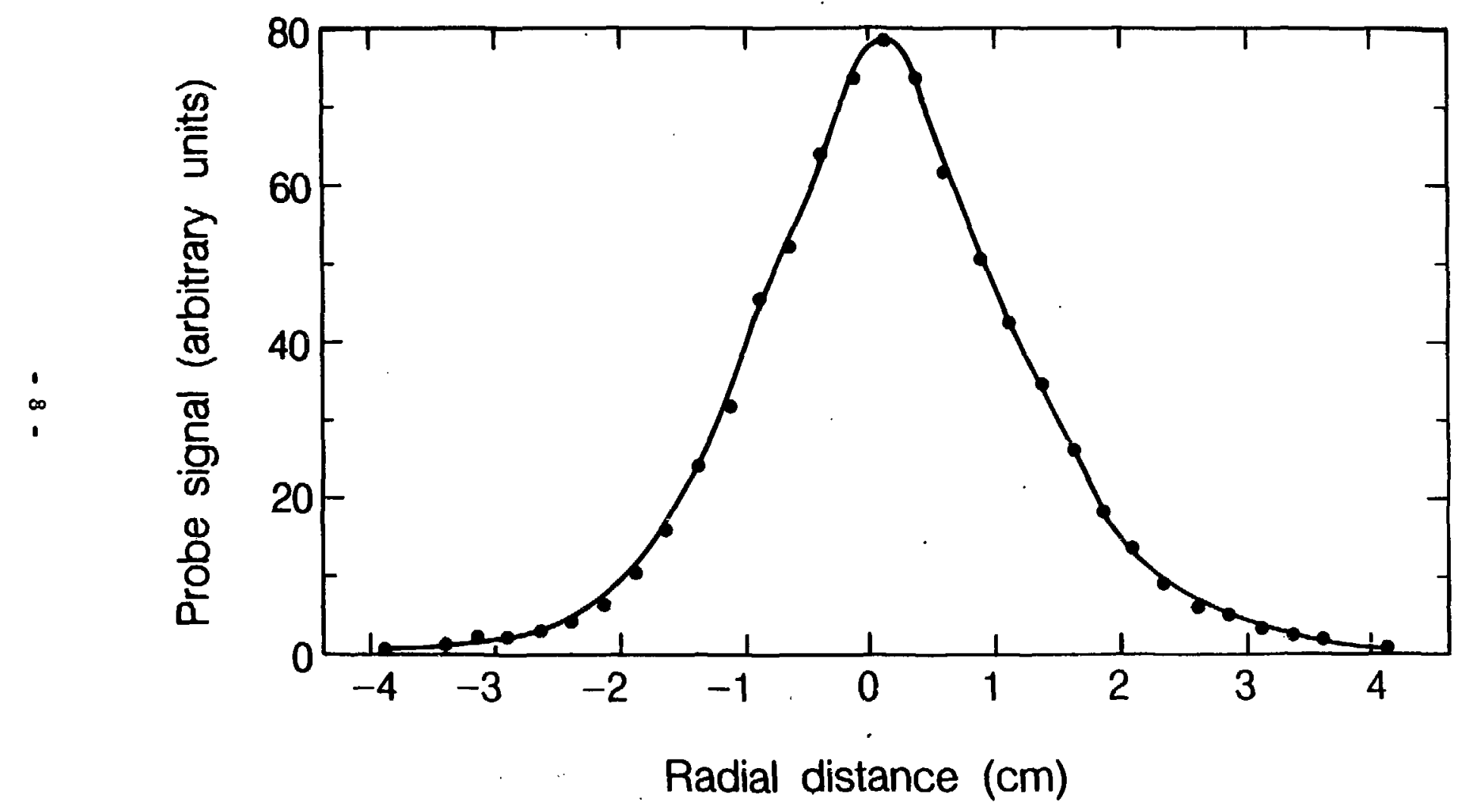

XBL 866-11625

Fig. 2 


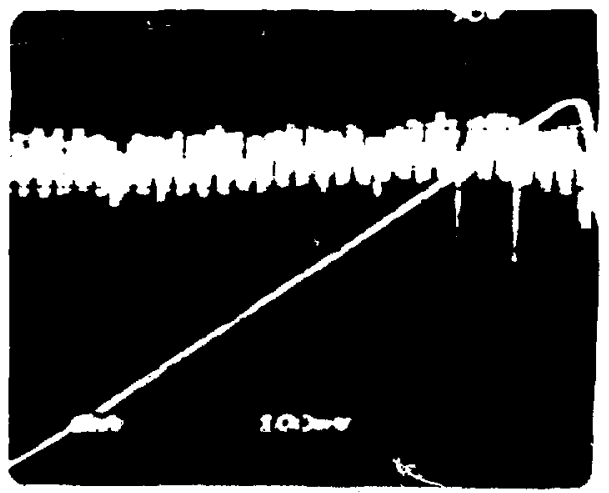

XBB 867-5708

Fig. 3 
This eport was done with euppon from the Depertment of Enery. Any concheione er opiliom expresed in wis mpat represeat solity these ef the

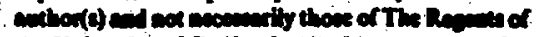

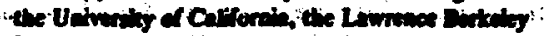

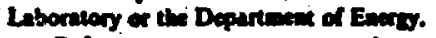

... Reforince to a company er product wis dow and inoply eppromil or moosumendation of the

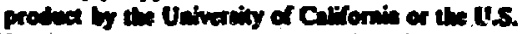
Depertinent of Eners to the excluaion of oflues then any be suitable. 